\title{
Microbial Quality of Traditionally Dried Fish Products from Selected Parts of Ethiopia
}

\author{
Bezuayehu Gutema*, Fikadu Hailemichael \\ Food Science and Nutrition Research, National Fishery and Aquatic Life Research Center, Ethiopian Institute of Agricultural Research, Sebeta, \\ Ethiopia
}

Email address:

bezuayehug7@gmail.com (B. Gutema)

${ }^{*}$ Corresponding author

\section{To cite this article:}

Bezuayehu Gutema, Fikadu Hailemichael. Microbial Quality of Traditionally Dried Fish Products from Selected Parts of Ethiopia. Frontiers in Environmental Microbiology. Vol. 7, No. 1, 2021, pp. 1-5. doi: 10.11648/j.fem.20210701.11

Received: January 18, 2021; Accepted: February 7, 2021; Published: March 4, 2021

\begin{abstract}
Dried fish is a rich source of protein, lipid and minerals that can serve as a promising source of nutrients to alleviate malnutrition in low-income countries. Nowadays, fish drying is becoming an increasing practice to extend the shelf life of excess catch in areas where other preservation mechanisms such as cold storage are scarce. However, since the drying is often performed in a rural setting with poor hygienic conditions, the microbial quality of such products is uncertain. This study was conducted to evaluate the microbial quality of traditionally dried fish products from sites around the lakes of Tana, Ziway and Chamo, where fish drying is commonly practiced in Ethiopia. Eighteen composite samples were analyzed to determine the microbial load and water activity. High microbial load was recorded in most of the dried fish samples as indicated by total viable count $\left(10^{5}\right.$ to $10^{7}$ $\mathrm{cfu} / \mathrm{g})$; lactic acid bacteria $\left(90^{1}\right.$ to $\left.10^{8} \mathrm{cfu} / \mathrm{g}\right)$; total coliforms $\left(<10\right.$ to $\left.10^{4} \mathrm{cfu} / \mathrm{g}\right)$, and yeast and molds $\left(10^{3}\right.$ to $\left.10^{5} \mathrm{cfu} / \mathrm{g}\right)$. The water activity value of all the dried fish samples was below 0.80 , indicating the adequacy of the drying since the growth of pathogenic bacteria is not expected at a water activity below 0.86 . However, a lack of hygiene during processing and handling was generally noticed. Hygienic processing and process standardization are required to improve the microbial quality of the dried fish.
\end{abstract}

Keywords: Dried Fish, Microorganisms, Water Activity, Contamination

\section{Introduction}

Fisheries contribute a substantial role in reducing food and nutrition insecurity for the very poor in most developing countries. Because of its incredible nutrient composition, the contribution of fish for proper nourishment and health is a widely documented fact. Fish is rich in quality protein with high bioavailability of essential amino acids, essential fatty acids and minerals such as iron, zinc, calcium, vitamin A, and vitamin B12, which in most cases lack from staple diets in low-income countries like Ethiopia [1]. In addition to the importance for proper nutrition, the role of fish consumption in promoting health has been widely declared. However, the unique nutrient composition of fish is not only preferred by humans but also made the fish a suitable medium for the growth and multiplication of microorganisms. As a result, the fish might become spoiled and unsafe for human consumption rapidly than other perishables unless preserved properly [2-4].

Different techniques have been employed to keep fish safe and extend the shelf life without a significant loss of quality. Cold storage being the preferred method, limitations to fulfill storage facilities such as refrigerators usually force small scale fish producers to look for alternative technologies for the preservation of their produce. Fermentation, drying and smoking could be the most frequently used alternatives applied worldwide to preserve fish for a long period. In Ethiopia, fish fermentation and smoking are rarely practiced but drying is common in Gambella riverine fishery and lake fisheries in Ziway, Chamo and Tana.

Traditional drying is usually practiced in rural settings in poor hygienic condition often leading to microbial contamination. In addition to the lack of hygiene, contaminants such as air, dust, contaminated water, and soil could also adversely affect the quality of dried fishes [5]. The presence of microorganisms in high numbers specially pathogens of known food safety concern could affect consumer health. Evaluating the level of contamination is necessary to know the safety of dried fish and ensure whether 
it is safely edible or not.

Qualitative and quantitative investigation of bacterial and fungal contaminants are often used to evaluate the safety level of dried fish products. Besides, the water activity of dried fish powder could also indicate the types of microbial contaminants. Limited information is available on the microbial safety of dried fish products in Ethiopia. This study was carried out to evaluate the microbial load of locally prepared dried fish products from Lake Ziway, Lake Chamo and Lake Tana sites in Ethiopia.

\section{Materials and Methods}

\subsection{Sample Collection}

Samples were collected from major dried fish producers located based on Lake Tana, Lake Ziway and Lake Chamo. From the Lake Tana site, samples were collected from Bahirdar, Werota and Enfranz sub-sites which are located in the south, east and northern parts of Lake Tana respectively. In the lake Chamo site, samples were collected from two sub-sites namely Gint and Dedo sub-sites. In lake Ziway, the majority of dried fish producers are found only on the Tulu gudo island, from which samples were collected. Description of all the samples is presented in (Table 1).

Table 1. Sample description.

\begin{tabular}{llll}
\hline Location & Sub-site & Species & Sample code \\
\hline \multirow{3}{*}{ Lake Tana } & Bahirdar & L. barbus & BB \\
& Werota & L. barbus & WB \\
& Enfranz & C. gariepinus & EG \\
Lake Chamo & Gint & L. niloticus & GN \\
& Dedo & C. gariepinus & DG \\
Lake Ziway & Tulu gudo & C. carpio & TC \\
\hline
\end{tabular}

From each sampling sub-site, samples were purchased from six randomly selected dried fish producers. Depending on the size of dried fish, three to six dried fish were aseptically collected for each species and kept as one sample in a sterile polyethylene package. The samples were then immediately transported to the National Fishery and Aquatic Life Research Center (NFALRC) laboratory for analysis.

\subsection{Microbial Analysis}

\subsubsection{Total Bacterial Count (TBC)}

Plate Count Agar (PCA) was used to determine the total microbial load of fish. Using separate sterile pipettes, decimal dilutions of $10^{-1}$ to $10^{-8}$ of sample homogenate was prepared by transferring $1 \mathrm{ml}$ of the previous dilution to $9 \mathrm{ml}$ of sterile peptone water. The dilutions were mixed using a vortex mixer, and $1 \mathrm{ml}$ of appropriate dilution was transferred into separate, duplicate, appropriately marked and sterilized Petri dishes. Then, PCA was cooled to $45 \pm 1^{\circ} \mathrm{C}$ and $15-20 \mathrm{ml}$ of the medium was added to each plate within 15 min of original dilution. After that, the sample dilutions and agar medium were mixed thoroughly and uniformly by alternate rotation and back-and-forth motion of plates on a flat level surface. Then, the agar was left to solidify for 15 minutes and the solidified Petri-dish was inverted and incubated promptly for $48 \pm 2 \mathrm{~h}$ at $35^{\circ} \mathrm{C}$. Finally, the number of Colonies was counted and multiplied by the dilution factor to calculate the total colonies forming units per gram of sample [6].

\subsubsection{Total Coliform Count (TCC)}

Violet Red Bile Agar was used to determine total coliform bacteria following the standard method [7]. From the homogenate, $1 \mathrm{ml}$ of serially diluted $\left(10^{-1}\right.$ to $\left.10^{-4}\right)$ sample was transferred into $9 \mathrm{ml}$ sterilized peptone broth in test tubes. The dilutions were mixed using a vortex mixer. Then $1 \mathrm{ml}$ of appropriate dilution was transferred into separate, duplicate, appropriately marked and sterilized Petri dishes. Then, 15-20 $\mathrm{ml}$ of the medium was added to each plate within $15 \mathrm{~min}$ of original dilution. After that, the sample dilutions and agar medium were mixed thoroughly and uniformly by alternate rotation and back-and-forth motion of plates on a flat level surface. Then, the agar was left to solidify for 15 minutes and the solidified Petri-dish was inverted and incubated promptly for $48 \pm 2 \mathrm{~h}$ at $35^{\circ} \mathrm{C}$. Finally, the number of Colonies were counted and multiplied by the dilution factor to calculate the total colonies forming units per gram of sample.

\subsubsection{Lactic Acid Bacteria (LAB)}

MRS agar was used to determine Lactic Acid Bacteria according to the standard method [8]. From the homogenate, 1 $\mathrm{ml}$ of serially diluted $\left(10^{-1}\right.$ to $\left.10^{-8}\right)$ sample was transferred into $9 \mathrm{ml}$ sterilized peptone broth in test tubes. The dilutions were mixed a vortex mixer. Then $1 \mathrm{ml}$ of appropriate dilution was transferred into separate, duplicate, appropriately marked and sterilized Petri dishes. Then, $15-20 \mathrm{ml}$ of the medium was added to each plate within 15 minutes of original dilution. After that, the sample dilutions and agar medium were mixed thoroughly and uniformly by alternate rotation and back and forth motion of plates on a flat level surface. Then, the agar was left to solidify for 15 minutes and the solidified Petri-dish was inverted and incubated in an anaerobic jar at $37^{\circ} \mathrm{C}$ for 48 hours.

\subsubsection{Yeast and Mold}

Yeast and molds were determined using potato dextrose agar following a standard procedure [9]. From the homogenate, $1 \mathrm{ml}$ of serially diluted $\left(10^{-1}\right.$ to $\left.10^{-5}\right)$ sample was transferred to $9 \mathrm{ml}$ sterilized peptone broth in test tubes. The dilutions were mixed using a vortex mixer. Then $1 \mathrm{ml}$ of appropriate dilution was transferred into separate, duplicate, appropriately marked and sterilized Petri dishes. Then, 15-20 $\mathrm{ml}$ of the medium was added to each plate within $15 \mathrm{~min}$ of original dilution. After that, the sample dilutions and agar medium were mixed thoroughly and uniformly by alternate rotation and back-and-forth motion of plates on a flat level surface. Then, the agar was left to solidify for 15 minutes and the solidified Petri-dish was inverted and incubated promptly for 5 days at $25^{\circ} \mathrm{C}$. Finally, the number of colonies was counted and multiplied by the dilution factor to calculate total yeast and molds per gram of sample. 


\subsection{Water Activity $\left(a_{w}\right)$}

Water activity was measured by a portable water activity meter. The sensor head was calibrated for 3 hours by putting special paper supplied with the instrument on a sample cup and moistened with the saturated barium chloride solution. After one and half hours of calibration, the instrument was adjusted to 0.90 . Then the sample was put for 3 hours in a disposable cup, completely covering the bottom of the cup. The result was recorded after 3 hours [10].

\subsection{Statistical Analysis}

Data were analyzed using JMP Pro version 13 software. Comparisons between means of microbiological parameters for the different samples were carried out using Analysis of Variance (ANOVA) and results with $\mathrm{p}$ values $<0.05$ were considered statistically significant. Further comparisons between mean values of statistically significant parameters were done using Tukey`s multiple comparison test.

\section{Results and Discussion}

Table 2 Microbial quality and water activity of dried fish products in Ethiopia.

\begin{tabular}{|c|c|c|c|c|c|c|}
\hline Sample & Total viable count & Total coliforms & Lactic acid bacteria & Yeast and mold & S.aureus & $\mathbf{a}_{w}$ \\
\hline $\mathrm{BB}$ & $3.08 \pm 1.36 \times 10^{7 \mathrm{ab}}$ & ND & $1.16 \pm 0.52 \times 10^{6 b}$ & $8.17 \pm 6.63 \times 10^{5 a}$ & $1.59 \pm 1.71 \times 10^{5 \mathrm{a}}$ & $0.75 \pm 0.01^{\mathrm{ab}}$ \\
\hline WB & $3.65 \pm 3.09 \times 10^{6 \mathrm{bc}}$ & $1.94 \pm 0.4 \times 10^{\mathrm{b}}$ & $4.45 \pm 0.93 \times 10^{3 \mathrm{~b}}$ & $4.57 \pm 0.85 \times 10^{3 a}$ & $2.79 \pm 2.44 \times 10^{5 \mathrm{a}}$ & $0.77 \pm 0.03^{\mathrm{b}}$ \\
\hline EG & $9.76 \pm 5.56 \times 10^{6 \mathrm{bc}}$ & $8.1 \pm 0.8^{\mathrm{b}}$ & $6.66 \pm 1.04 \times 10^{4 b}$ & $2.47 \pm 2.43 \times 10^{5 \mathrm{a}}$ & $5.18 \pm 2.08 \times 10^{5 \mathrm{a}}$ & $0.79 \pm 0.01^{\mathrm{a}}$ \\
\hline GN & $5.36 \pm 1.40 \times 10^{5 \mathrm{c}}$ & $2.73 \pm 0.09 \times 10^{4 a}$ & 9. $00 \pm 0.01 \times 10^{1 \mathrm{a}}$ & $1.94 \pm 0.31 \times 10^{4 a}$ & $4.34 \pm 0.95 \times 10^{4 a}$ & $0.70 \pm 0.02^{\mathrm{b}}$ \\
\hline DG & $5.75 \pm 4.31 \times 10^{6 \mathrm{c}}$ & $2.46 \pm 2.10 \times 10^{4 a}$ & $2.90 \pm 0.83 \times 10^{8 b}$ & $1.15 \pm 1.06 \times 10^{4 a}$ & $3.95 \pm 2.74 \times 10^{4 a}$ & $0.73 \pm 0.02^{b}$ \\
\hline $\mathrm{TC}$ & $4.20 \pm 1.40 \times 10^{5 \mathrm{a}}$ & $4.21 \pm 5.15 \times 10^{2 b}$ & $6.48 \pm 0.98 \times 10^{3 \mathrm{~b}}$ & $2.66 \pm 0.61 \times 10^{3 a}$ & $2.82 \pm 1.80 \times 10^{4 a}$ & $0.72 \pm 0.01^{\mathrm{b}}$ \\
\hline$P$ value & 0.0013 & 0.0025 & $<0.0001$ & 0.1745 & 0.04 & 0.0013 \\
\hline
\end{tabular}

Mean \pm Standard Deviation (Mean \pm SD) of microbial quality indicators obtained from dried fish samples are presented in (Table 2).

\subsection{Total Viable Count (TVC)}

The total viable count is one of the indicators for the quality of dried fish. The population of TVC recorded in this study varies from $4.20 \times 10^{5}$ in $\mathrm{TC}$ to $3.08 \times 10^{7}$ in $\mathrm{BB}$ samples. Similar studies were conducted in dried fish and reported total bacterial count ranging from $10^{5}$ to $10^{9}$ [11]. The total bacterial load generally indicates the poor microbiological quality of all the tested samples. Compared to the most frequently used microbial criteria, the bacterial load of all tasted samples under this study are below the standard [12].

\subsection{Total Coliforms}

In this study, coliforms were detected in more than $80 \%$ of the tested dried fish samples. All the tested samples from lake Tana (BB, WB \& EG) showed a coliform count less than 100 while the other tested samples had a total coliform ranging from 421 to 27,300 . Although similar finding has been reported from previous research [13], standards declare that coliforms should not exceed 100 in a quality dried fish product [14]. The water could be the major source for the contamination by coliforms. Besides, lack of hygiene during the drying process which might include the usage of dirty processing equipment and poor handling of the fish might have contributed to the presence of coliforms in such numbers.

\subsection{Lactic Acid Bacteria (LAB)}

The highest and lowest counted LAB were $2.9 \times 10^{8}$ in DG and $9 \times 10$ in GN. The presence of LAB in such a high number could have little implication regarding the spoilage of the product since such a large number of LAB could exist for several weeks before the fish is rejected organoleptically [15].

\subsection{Yeasts and Molds}

Yeast and mold count were recorded ranging from $2.66 \times$ $10^{3}$ to $8.17 \times 10^{5}$ in TC and BB samples respectively. The presence of yeasts and molds in such dried food products is because of their higher tolerance in reduced water activity levels in contrast to pathogenic bacteria which does not grow at water activity levels below 0.86 [16].

\subsection{Staphylococcus Aureus}

The S. aureus count of all the samples was in a close proximity ranging from $2.82 \times 10^{4}$ in TC to $5.18 \times 10^{5}$ in EG samples. S. aureus is known for a unique ability to survive in harsh conditions such as low water activity and salt content. Since the growth of this species is possible in a water activity ranging from 0.83 to 0.99 [17], necessary precautions to avoid an increase in water activity is required. Besides, the dried fish products should be well cooked before consumption to ensure safety.

\subsection{Water Activity (AW)}

All the tested samples showed a water activity value below 0.8 within a range between 0.70 to 0.79 . Water activity is an important factor in food preservation since it provides information on the quality deterioration including the growth of microorganisms [16, 18]. Most pathogenic bacterial growth and toxin production are highly hindered at low water activity. However, the survival of microorganisms is common at water activity levels below the values found in this study. This might pose a risk to consumers due to the presence of infectious bacteria such as Salmonella and Escherichia coli strains [19]. 


\section{Conclusion}

The microbiological quality of traditionally prepared dried fish was studied from villages located around three lakes in Ethiopia. Based on the level of bacterial load, all samples were heavily loaded with bacteria irrespective of the sampling sites. However, a pronounced load of coliforms was observed in samples from GN, DG and TC, which could be sourced from contaminated water, unsanitary utensils and/or poor hygienic handling during the preparation of the dried fish. The recorded water activity level i.e., $<0.80$ could reflect that the drying process is sufficient to remove the free water which could have been used by pathogenic bacteria growth and toxin production. It is generally noted that although dried fish could serve as a nutritious component in a diet, the microbial quality of these products is inferior and needs improvement in preparation and handling processes.

\section{Recommendations}

The drying process in all study sites was undertaken in open-air conditions with a high vulnerability to physical and biological contaminants such as dust and insects respectively. Therefore, conventional sun drying equipment would have a significant contribution to limit contamination from the environment. Also, drying processes in all sites were not standardized and vary from place to place indicating the importance of standardizing the drying process to meet certain safety criteria. This could be done by researching to determine the time of drying, required ingredients such as salt, and their amount depending on the environmental condition and intrinsic characteristics of each species. Furthermore, the existing good practices should be shared from one place to the other. One of the main finding in this study is identifying the pros and cons of the drying process in each study site. It was observed that the fish drying process in sites around lake Tana (Bhirdar, Enfranz and Werota) well exploits the preservative effect of salt by adding it as a major preservative. On the other side, the fish drying process in sites around Lake Ziway (Tulu gudo) and Lake Chamo (Gint and Dedo) relies solely on the sun to dry and extend the shelf life of the fish. However, in the later sites, the edible portion of the fish is thinly striped using a knife to accomplish fast-drying while the former sites usually dry the whole edible fillet without the necessary dicing/striping. Based on this fact, it is recommended to share the experience of salting technology and sun-drying procedure between the producers in the different sites. To achieve expected improvement in quality, responsible bodies should provide adequate training for the dried fish producers on the topic of the hygienic fish drying process, and packaging and storage conditions. In the end, authorities should monitor dried fish producers and provide necessary measures to ensure the wider consumers are protected against unsafe products in the market.

\section{References}

[1] Dewey, K. G., \& Brown, K. H. (2003). Update on technical issues concerning complementary feeding of young children in developing countries and implications for intervention programs. Food and nutrition bulletin, 24 (1), 5-28.

[2] Khan, M. A. A. and Khan, Y. S. A. 2001. Insect infestation and preventive measures in dry fish storage of Chittagong, Bangladesh. International Journal of Biological Sciences 1: 963-965.

[3] Musa, U., Hati, S. S., Adamu, Y. I. and Mustapha, A. 2010. Pesticides residues in smoked fish samples from North-Eastern Nigeria. Journal of Applied Sciences 10: 975-980.

[4] Dewi, R. S., Nurul Huda, G. and Ahmad, R. 2011. Changes in the physicochemical properties, microstructure and sensory characteristics of shark dendeng using different drying methods American Journal of food Technology 6: 149-157.

[5] FAO, 1982. Reference Manual to codes of practices for fish and fishery products. Food and Agriculture Organization, Rome.

[6] APHA, 1992. Compendium of methods for the microbiological Examination of foods, 3rd ed., C. Vander dent, and splittstoesser, D, (Eds), APHA, Washington Dc 2: 1264 pp.

[7] Wehr, H. M., Frank, J. F., \& American Public Health Association (Eds.). (2004). Standard methods for the examination of dairy products (pp. 327-404). Washington, DC: American Public Health Association.

[8] HC, S., RAI, A. K., PM, H. \& NM, S. 2011. Isolation and characterization of potential lactic acid bacteria (LAB) from freshwater fish processing wastes for application in fermentative utilisation of fish processing waste. Brazilian Journal of Microbiology, 42: 1516-1525.

[9] Huque, R., Islam, M. \& Khatun, A. 2013. Microbiological quality improvement of dried fish by gamma irradiation and assessment of food value upon irradiation with respect to biochemical aspect. International Research Journal of Pharmaceutical and Applied Sciences, 3: 1-5.

[10] Bassal, A.; asseur, J. (1992) Measurement of water activity at high temperature. In: Proceedings International Drying Symposium. A. S. Mujumdar (ed.). Elsevier SciencePublishers B. V. 313-321.

[11] Immaculate, K., Sinduja, P., Velammal, A., \& Patterson, J. (2013). Quality and shelf-life status of salted and sun-dried fishes of Tuticorin fishing villages in different seasons. International Food Research Journal, 20 (4).

[12] Surendran, P., Nirmala Thampuran, K. V., Narayanannambiar, and Lalitha, K. V. 2006. Laboratory manual on microbiological examination of seafood, CIFT, Cochin, 2nd edn.

[13] Sivashanthini, K, Vivekshan, S, Reval and A. C. Thavaranjit, 2012. Comparative Study on Organoleptic, Microbiological and Biochemical Qualities of Commercially and Experimentally Prepared Salted and Sun Dried Talang Queen Fish, Scomberoides commersonianus. Asian Journal of Animal and Veterinary Advances, 7: 1279-1289.

[14] Sri Lanka Standards 2007. Specification for dried fish, SLS 643: 2007, Sri Lanka Standards Institution, Colombo, Sri Lanka. 
[15] Gram, L., \& Huss, H. H. (1996). Microbiological spoilage of fish and fish products. International journal of food microbiology, 33 (1), 121-137.

[16] Shafiur Rahman, M., \& Labuza, T. P. (2007). Water activity and food preservation. Handbook of food preservation- $2^{\text {nd }}$ edition, edited by M. Shafiur Rahman, CRC Press Taylor \& Francis Group, Boca Raton.

[17] FDA, (2012). Handbook of foodborne pathogenic microorganisms and natural toxins. Food and Drug Administration, Silver Spring, MD, USA.
[18] Nguyen, M. V., Arason, S., \& Eikevik, T. M. (2014). Drying of fish. Seafood processing: Technology, quality and safety, 161-175.

[19] Tapia, M. S., Alzamora, S. M., \& Chirife, J. (2020). Effects of water activity (aw) on microbial stability as a hurdle in food preservation. Water activity in foods: Fundamentals and applications, 323-355. 